\title{
Research on Regional Logistics Integration of Wuhan City Circle under the Background of Big Data
}

\author{
Yu Zhao \\ Department of Business Administration \\ Hubei Finance and Taxation College \\ Wuhan, Hubei 430064, China
}

\begin{abstract}
Wuhan city circle refers to the city circle which is made up of various prefecture cities with the radius of 100 kilometers around the center of Wuhan. The establishment of efficient Wuhan city circle regional logistics integration system can promote the coordinated development of the urban circle, and adjust the industrial structure, and reduce the logistics costs. In Wuhan city circle the e-commerce rises rapidly in this internet era, the big data technology for Wuhan city circle regional logistics integration system construction, development and innovation has very important application value. Relying on the use of big data technology optimizes Wuhan city circle regional logistics integration of cyber source configuration, and forms Wuhan city circle mutual integration, reduces costs effectively and improves logistics efficiency, realizes the target of regional logistics integration in Wuhan city circle.
\end{abstract}

Keywords-Big data; Wuhan City Circle; Logistics Integration

\section{INTRODUCTION}

Wuhan city circle refers to the scope of Wuhan as the center, radiation around $100 \mathrm{~km}$ radius. It consists of all prefecture level cities, including Wuhan and eight peripheral cities of Huangshi, Ezhou, Xiaogan, Huanggang, Xianning, Xiantao, Qianjiang and Tianmen. Wuhan city circle is a central node connecting the Pearl River Delta, Yangtze River Delta and the Western Economic Zone in the region of Hubei Province. Wuhan city circle is the most concentrated production factors and the most competitive region, and also the one of the most development potential regions in mid-west.

\section{A. Logistics Development Survey of Wuhan City Circle}

At present, the Wuhan city circle is still nine independent administrative regions. Each determines its own policies, just considers the other subjects of interest and the interests of the entire region as the factors to achieve their own interests. It will not consider the interests of other areas as main targets to achieve. The target of regional economy is still subject to administrative target. Therefore, when self-interest conflicts with regional interests, each often considers more of its own interests, and not the overall planning of regional logistics coordination and development. The state-owned economy of Wuhan city circle area accounts for the larger proportion, and the conversion system is slow, and the main market is not active, and the market system is not perfect. It hinders the implementation of fair logistics market environment.

\section{B. Significance of Wuhan City Circle Regional Logistics Integration}

Theory shows that modern logistics industry is the product of regional economic development to a certain extent. To measure the overall strength of the economy and the degree of modernization is marked by the level of development of logistics in a region. Because of the industrial base of each city in Wuhan city circle, the development level of logistics industry and regional logistics efficiency are quite different, and the logistics industry has the typical characteristics of network service, such differences will hinder the development of Wuhan city circle economy to a certain extent.

The integration of regional logistics is on the existing basic conditions to implement seamless link, to form a comprehensive logistics system of multi-level and multi-function, quick operation, to accelerate the regional economic integration and coordinated development, to promote regional economic integration. Therefore, speeding up the coordinated development of regional logistics integration in Wuhan city circle is of great significance to realize the economic integration, the concentration of industrial clusters and the optimal allocation of resources.

\section{Goal of Wuhan City Circle Regional Logistics Integration}

According to the development of Wuhan city circle logistics and economic integration, we shall establish and use regional unified big data logistics public information platform. The structure problem of long dispersed and separated in logistics network can solve by reconfiguration in Wuhan city circle logistics. To promote the rational flow of the existing Wuhan city circle logistics cyber source elements and to optimize the combination of sources, we shall promote the advantage sharing and combination of Wuhan city circle logistics network construction of, adapt to the economic development in Wuhan city circle, meet the people's life demand with low cost and high efficiency. 


\section{INFLUENCE OF BIG DATA FOR REGIONAL}

\section{LOGISTICS INTEGRATION OF WUHAN CITY CIRCLE}

In the age of internet, internet of things and information, data as an intangible asset has big value. Especially in the logistics industry, almost all of the logistics service will produce a large amount of data. If we can classify these massive data, overall analysis and the depth excavation, a significant impact will be on the operation efficiency and management mode for the development of the logistics industry. The combination of big data technology and logistics industry in the application can produce three advantage sat least. The first is the logistics services more personalized and fine; the second is the logistics process with the characteristics of digital, intelligent, and efficient; and the third is the big data to form platform, integration and sharing, to promote the growth of the logistics economy [1].

In the internet era of e-commerce rapid rising in Wuhan city circle, Wuhan city circle logistics economy is a new growth point to promote the development of logistics service industry. Therefore, the big data technology has very important application value to the construction, development and innovation of Wuhan city circle regional logistics integration system. Big data technology impact on regional integration of logistics organization network of Wuhan city circle, infrastructure network and information network is shown in Figure 1. It provides the basis and theoretical support for the regional logistics integration reconstruction of Wuhan city circle in this data era [2].

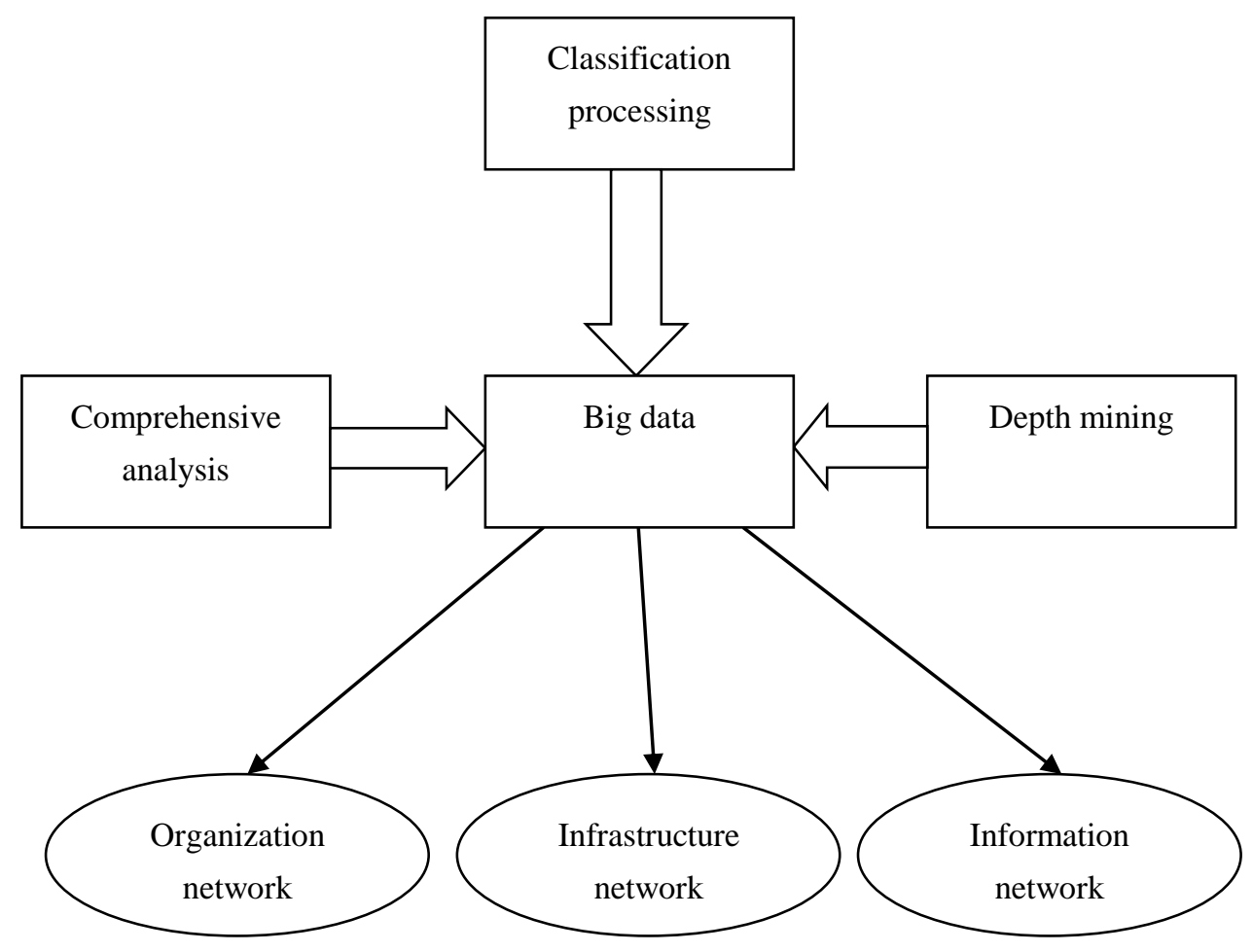

Fig. 1. The Impact of Big Data on the Regional Logistics Integration of Wuhan City Circle

\section{A. Influence by Big Data forOrganization Network of Wuhan City Circle Regional Logistics Integration}

Logistics organization is the main participants of logistics activities, and it takes logistics activities and coordination. From the perspective of logistics enterprise, the logistics organization composes of various departments of logistics enterprises. From the perspective of the logistics industry, logistics organization is the main body involved in the logistics activities of the whole society, such as the different logistics enterprises and government departments. Wuhan city circle regional logistics integration organization network refers to all kinds of interconnected Wuhan city circle regional logistics organization network system. With the rapid development of e-commerce in Wuhan city circle, the major logistics organizations have layout Wuhan city circle, such as Ali group's rookie network, Jingdong group's XianFeng station plan. With large data information technology, logistics organizations can achieve internal and external information sharing and integration, achieve organizational network optimization and reorganization, and improve logistics efficiency.

\section{B. Influence by Big Data forInfrastructure Network of Wuhan City Circle Regional Logistics Integration}

Wuhan city circle regional logistics integration infrastructure includes Logistics Park, logistics node, transportation facilities, storage system facilities, packaging and loading and unloading system facilities. With the application of information technology in the logistics industry, a lot of logistics tools have characteristics of information and digital, such as picking system, radio frequency identification (RFID), intelligent storage and handling equipment and global positioning system (GPS) transport tool. Through extensive 
application of high technology and intelligent technology in the field of logistics infrastructure, the logistics facility network has the large data characteristics. The application of correlation analysis technology will take a profound impact on the logistics activities.

\section{Influence by Big Data forInformation Network of Wuhan City Circle Regional Logistics Integration}

Wuhan city circle regional logistics integration information network is an important support for logistics network and an important guarantee for normal logistics activities. Fragmentation, scattered data lacks of application value. With the help of large data mining and association technology, we can make fragmentation information to form a connection, dig out its potential value. Big data platform + logistics mode has become a development direction of the logistics industry. The logistics mode allows participating enterprises or individual to carry out a full range of information sharing, such as demand information, time, distribution route, to fulfill logistics operation system overall optimization goal, to realize the win-win situation of participants.

\section{SPECIFIC MeAsures For WuHAN CITY CiRCle Logistics}

\section{INTEGRATION UNDER THE BACKGROUND OF BIG DATA}

Compared with decentralized management, single function, the original technology in transportation business, modern logistics industry belongs to the intensive high-tech technology and high value-added enterprise with the features of structure complex, assets supererogation, labor skilled. From this point of view, the establishment of the city circle logistics system is conducive to the development of industrial structure to the height of the city circle. In the economic globalization, to achieve a reasonable division of between regions, coordinate regional logistics, business flow, information flow, capital flow, technology flow, are the subjects to study and resolve for the regional economic and social development. In regional big business, big market and circulation needs the development of regional logistics. City circle logistics network structure of a stable and efficient operation, can not only reduce the wear between the components and the transaction cost, reduce the user cost of cyber source and elements, but also enlarge the functions of the various elements, and improve the whole network efficiency, make use of regional advantages. Reasonable city circle logistics system is conducive to centralize logistics processing, to achieve the amount of intensive. Reasonable regional logistics can optimize the allocation of regional resources, reduce the total cost of society, improve regional economic competitiveness, and promote regional sustainable development [4].

\section{A. Cost Savings Analysis of Wuhan City Circle Regional Logistics Integration}

Logistics costs are divided into general cost and special cost. Special cost of logistics refers to the cost of transportation, packing, handling and so on caused by the displacement of the place (or position) of the entity. The general cost of logistics refers to the whole cost of the entity and value transformation including production, circulation and consumption.
Related data of Wuhan city circle logistics costs as shown in table 1 [5].

TABLE I. 2014WuHAN CITY CiRCLE LOGISTICS COSTSUNIT: BILLION $\mathrm{RMB}$

\begin{tabular}{|c|c|c|c|c|}
\hline City & GDP & $\begin{array}{c}\text { Logistics } \\
\text { Costs } \\
(16.6 \% \\
\text { GDP) }\end{array}$ & $\begin{array}{l}\text { World } \\
\text { Average } \\
\text { Logistics } \\
\text { Costs } \\
(11.6 \% \mathrm{GD} \\
\text { P) }\end{array}$ & $\begin{array}{c}\text { Save Costs } \\
\text { of the } \\
\text { Using } \\
\text { Modern } \\
\text { Logistics } \\
(5 \% \text { GDP } \\
)\end{array}$ \\
\hline Wuhan & 1006.948 & 167.153 & 116.806 & 50.347 \\
\hline $\begin{array}{c}\text { Huang } \\
\text { shi }\end{array}$ & 121.856 & 20.228 & 14.135 & 6.093 \\
\hline $\begin{array}{c}\text { Huang } \\
\text { gang }\end{array}$ & 147.715 & 24.521 & 17.135 & 7.386 \\
\hline $\begin{array}{l}\text { Xian } \\
\text { ning }\end{array}$ & 96.425 & 16.007 & 11.185 & 4.821 \\
\hline $\begin{array}{l}\text { Xiao } \\
\text { gan }\end{array}$ & 135.472 & 22.488 & 15.715 & 6.774 \\
\hline Ezhou & 68.664 & 11.398 & 7.965 & 3.433 \\
\hline $\begin{array}{l}\text { Tian } \\
\text { men }\end{array}$ & 40.186 & 6.671 & 4.662 & 2.009 \\
\hline $\begin{array}{c}\text { Xian } \\
\text { tao }\end{array}$ & 55.227 & 9.168 & 6.406 & 2.761 \\
\hline $\begin{array}{l}\text { Qian } \\
\text { jiang }\end{array}$ & 54.022 & 8.968 & 6.267 & 2.701 \\
\hline Total & 1726.515 & 286.601 & 200.276 & 86.326 \\
\hline
\end{tabular}

Source: Hubei Statistical Yearbook. Hubei Provincial Bureau of statistics.2014.

Calculation principal: People's daily on July 2015 25, China's national development and Reform Commission revealed on July 20th that in 2015 China's logistics costs accounted for the proportion of GDP up to $16.6 \%$, higher than the world average of 5 percentage points [3].

Table 1 shows that the using of modern logistics, Wuhan city circle can save logistics costs amounting to $\$ 86.326$ billion RMB. It can be predicted that the establishment of regional logistics integration system is efficient for the relevant industry in the Wuhan city circle. Centralized purchasing, centralized transportation, centralized storage, centralized management, the specialization, scale, can effectively reduce the purchase cost, greatly achieve load rate, and make full use of personnel and logistics facilities. To do so, from the macro, to reduce the huge cost of logistics, to promote the coordinated development of city circle; from the middle, to adjust the industrial structure, to promote the rationalization and to 
upgrade of industrial structure; from the micro, to reduce the logistics cost, to increase the economic benefit, to improve production efficiency and social live standard.

\section{B. Guiding Ideology of Wuhan City Circle Regional Logistics Integration Reconstruction}

To promote Wuhan city circle regional logistics integration reconstruction, we use Wuhan city circle traffic information and policy environment as the basis, relying on the using of big data technology, and optimizing cyber source configuration, to form mutual support, mutual integration pattern, effectively to reduce the cost and to improve the logistics distribution efficiency, to realize Wuhan city circle regional logistics integration goal. Wuhan city circle regional logistics integration reconstruction strategic framework as figure 2 .

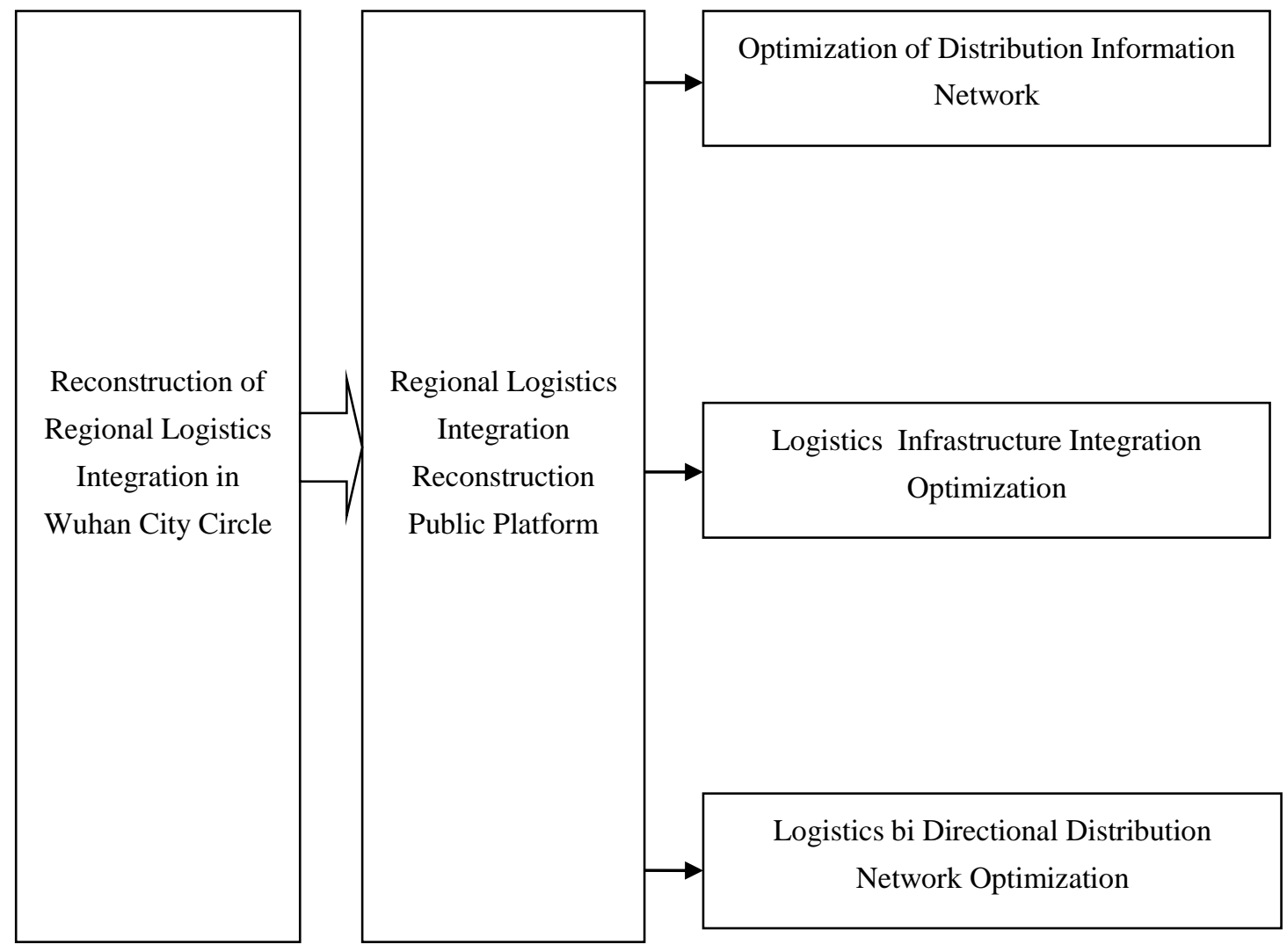

Fig. 2. Wuhan City Circle Regional Logistics Integration Reconstruction Strategic Framework

The guiding ideology of Wuhan city circle of regional logistics integration reconstruction: taking Wuhan city circle integration of regional logistics development planning as the basis, forward-looking and strategic height, relying on big data and using logistics public information plat form. Through the regional logistics network reconfiguration, the formation of organic unified city circle logistics network is established to integrate the space of Wuhan city circle. According to the principle of comparative advantage, we should not only attach importance to play the advantages of Wuhan city circle logistics distribution network, but also focus on reasonable division of labor, make up for the short board, form Wuhan city circle logistics network integration pattern.

\section{Optimization of Regional Logistics Distribution Information Network}

In order to establish an integrated network information platform, first we should establish a regional unified large data logistics network information public platform. It can be selected by the existing large-scale logistics enterprises through competitive advantage, but it also can be invested by government to establish regional logistics center information platform. All customer members focus on this big data information public platform for payment, settlement, transaction tracking, credit evaluation and logistics information in real time. Second we should establish regional unified large data logistics network information base. Based on the information platform for regional unified big data logistics network to collect Internet data information, the platform links and receives National Federation of logistics and related industries information, and horizontal docks the logistics information network of provinces. We use big data technology in the region to collect logistics information of car networking, logistics center, target customers, agricultural products and agricultural production materials etc. Through the classification of various logistics information, integration, storage, we can establish ecological wisdom logistics. Regional logistics data collected by network information database provides support for the integration of regional logistics network and the construction of information network management platform. 


\section{Optimization ofRegional Logistics Infrastructure Resources Integration}

Regional spatial integration is the material base of regional economic integration, and the primary task of building Wuhan city circle. To improve the transportation infrastructure is to accelerate the construction of highway among the other eight cities of Wuhan city circle, to realize the whole circle interweave, to arrange in crisscross pattern interconnection. Making full use of natural advantages of the Yangtze golden water way develops the river through sea transportation vigorously. Increasing the renovation of transport ships improves ship equipment level. Accelerating the intercity railway construction implements intercity rail transit. Relying on the Wuhan Tianhe Airport improves air cargo throughput capacity, and enhances the radiation range of the airport.

To promote the integration of regional logistics network reconfiguration of Wuhan city circle is not reconstruction the existing regional logistics network of Wuhan city circle, but re-optimizes the existing cyber source logistics configuration, implements integrated logistics construction of cyber source increment. These require government policy to promote, the main industries and enterprises to participate, through the operation of the market.

\section{E. Optimization of Regional Logistics bi Directional Distribution Network}

Bi directional distribution refers to the two-way logistics and product sales for various elements of production and consumer goods, and it works interaction, interrelates and constitutes an organic whole. It includes the material procurement, product processing, storage and distribution, including the product terminal logistics and consumer goods distribution. The development and application of bidirectional logistics in the urban circle plays an important role in promoting the city circle docking and effectively ensuring the residents' safe consumption. Bi directional distribution may seem simple, but from the perspective of supply chain management, it relates to the commodity supply organization, storage of distribution center, sorting ability, transportation planning, vehicle scheduling and information system support. It is a complex trade-off system. Through large data analysis and calculation, we can optimize regional logistics bi directional distribution network.

\section{CONCLUSION}

By means of big data, the logistics integration of Wuhan city circle is more personalized and refined, to present the characteristics of digitalization, intelligence, and high efficiency. Big data can reduce the wear and transaction costs of the elements of the city circle, and improve the efficiency of each functional element of the logistics. Big data makes the allocation of regional logistics resources more reasonable, which can greatly reduce the logistics operation cost of the whole region, and optimize the whole regional logistics system. We can promote regional logistics integration in Wuhan city circle through big data, improve regional economic and product competitiveness, and promote the coordinated development of regional economy in the whole city circle.

\section{REFERENCES}

[1] Tao Juncheng, Pan Lin, Ye Ping Chu. Urban and Rural Logistics Network Reconstruction in Era of Big Data [J]. China Circulation Economy, 2016 (11).

[2] Zheng Yu, Zhang Xumei. Relationship Between Logistics Circle and Wuhan City Circle [J]. Logistics Engineering and Management, 2009 (3).

[3] Yang Guomin. Last Year the Total Social Logistics Amounted to 220 Thousand Trillion RMB 30 Million Practitioners [N]. Economic Daily, 2016-01-07 (7).

[4] Ju Songdong, Xu Jie. Logistics Network Theory and its Research Significance and Methods[J]. China Circulation Economy, 2007 (8).

[5] Hubei Statistical Yearbook. Hubei Provincial Bureau of statistics.2014. 